\title{
Facilitating Access to Higher Education for People Seeking Asylum in Australia: Institutional and Community Responses
}

\author{
RACHEL BURKE, CAROLINE FLEAY, SALLY BAKER, LISA HARTLEY, AND REBECCA FIELD ${ }^{1}$
}

\section{Abstract}

Higher education remains unattainable for many people seeking asylum in Australia, where temporary visa status renders individuals ineligible for a range of government services including assistance with financing tertiary study. Many universities have responded by offering scholarships and other essential supports; however, our research indicates the challenges associated with studying while living on a temporary visa can affect the success of educational assistance. Here we highlight the importance of scholarships and other supports for facilitating access to tertiary study, particularly given the continuation of restrictive government policies, and identify the need for people seeking asylum to inform institutional and community responses.

\section{Résumé}

L'éducation supérieure demeure inatteignable pour plusieurs personnes demandant l'asile en Australie, où le statut rattaché au visa temporaire rend les individus inéligibles à une gamme de services, dont laide financière aux études postsecondaires. Plusieurs universités ont réagi en offrant des bourses et autres soutiens essentiels. Cependant, notre recherche indique que les obstacles liés au fait d'étudier tout en vivant avec un visa temporaire peuvent affecter le succès de l'aide aux études. Nous soulignons l'importance des bourses et d'autres types de soutien pour promouvoir laccès aux études postsecondaires, particulièrement dans le contexte de politiques gouvernementales restrictives, et identifions la nécessité pour les personnes demandeuses d'asile de contribuer aux réponses institutionnelles et communautaires.

1. This research was funded by the National Centre for Student Equity in Higher Education, Curtin University.

() R. Burke, C. Fleay, S. Baker, L. Hartley, and R. Field, 2020. This open-access work is licensed under a Creative Commons Attribution-NonCommercial 4.o International Licence, which permits use, reproduction, and distribution in any medium for non-commercial purposes, provided the original authorship is credited and the original publication in Refuge: Canada's Journal on Refugees is cited.
Cette ouvre en libre accès fait l'objet d'une licence Creative Commons Attribution-NonCommercial 4.o International License, laquelle autorise l'utilisation, la reproduction et la distribution de l'ouvre sur tout support à des fins non commerciales, pourvu que l'auteur ou les auteurs originaux soient mentionnés et que la publication originale dans Refuge: revue canadienne sur les réfugiés soit citée. 


\section{Introduction: The Australian Context}

The choice to participate in higher education ${ }^{2}$ is an important factor for many people seeking asylum in Australia (Hartley et al., 2018). Access to further education can provide people seeking asylum with important opportunities to develop and enhance capacities and knowledge to sustain their livelihoods; aiding resettlement, social inclusion, and personal life fulfillment (Fleay et al., 2016). However, the findings of our Australia-wide study indicate that restrictive government policies render tertiary education an unaffordable dream for most people seeking asylum (Hartley et al., 2018). While not the only group to be excluded from higher education in Australia, people seeking asylum face unique challenges to participation in tertiary studies due to the precarity of their visa status and the prevailing policy landscape.

Between 2012 and 2014, some 30,000 people seeking asylum came to Australia by boat. Prohibited from lodging an application for protection for up to four years after their arrival (Kaldor Centre, 2019; RCOA, 2018), these people came to Australia before August 13, 2012. They had not had their protection visa application finalized by September 18, 2013, or they arrived after August 12, 2012, and were not sent to offshore detention on Nauru or Papua New Guinea's Manus Island. With a change of federal government, this group was deemed a "legacy caseload," and in late 2014, legislation was introduced mandating that applications for protection could be submitted only at the invitation of the minister. ${ }^{3}$ These people have subsequently resided in community detention ${ }^{4}$ or lived in the community on temporary bridging visas while waiting for their claim for protection to be processed.

Significantly, people in the legacy caseload are not permitted to apply for permanent visas. If they are deemed eligible for protection, the Australian government issues these applicants one of two temporary visas: a 3-year temporary protection visa (TPV) or a 5-year safe haven enterprise visa (SHEV). While approximately $70 \%$ of people in the legacy caseload have now received a decision on their application for a TPV or SHEv, by March 2019 there were still 9,315 people awaiting an outcome (Kaldor Centre, 2019). Here we use the term "people seeking asylum" to refer to people who are either awaiting the outcome of their application for refuge and living in the community on a bridging visa or in community detention, or those deemed to be a refugee and granted a TPV or sHEV.
While most people seeking asylum have the right to study in Australia, they are ineligible for a range of services, including government assistance with financing tertiary study. Accordingly, people seeking asylum encounter barriers to tertiary enrolment that effectively deny them access to higher education in Australia. The temporary nature of their visa means the only pathway to tertiary studies available to the majority of people seeking asylum is to be granted admission as a full-fee-paying international student. Without government subsidies, the cost of an undergraduate degree is approximately AUD 30,000 per year (McCarthy \& Dauba, 2018), rendering higher education an unaffordable dream for most prospective students living on bridging or temporary visas.

\section{Institutional and Community Responses}

In recent years, a number of universities have responded to restrictive Australian government policies by creating ways to support access to higher education for people seeking asylum. Some institutions have introduced full or partial scholarships, stipends, part-time employment opportunities attached to scholarships, and schemes to help provide computers and other educational equipment. In 2018 , there were approximately 204 people seeking asylum studying in 23 universities across Australia via scholarships that met their full tuition fees (Hartley et al., 2018). Some state governments have also offered support for people to access vocational education and training (VET), including concession rates for some certificate-level courses.

Community organizations have also facilitated greater access to higher education, assisting asylum seekers to locate scholarships and navigate application processes. In this important work, community organizations have been supported by the Refugee Council of Australia's "Education for All" campaign, which raises awareness about the educational rights of people seeking asylum, advocates with state and federal governments, and provides details of scholarships. This initiative is now managed by the Refugee Education Special Interest Group, a national collective of advocates, scholars, and practitioners working to support greater access to education. ${ }^{5}$

While the last 5 years have seen rapid growth in awareness of the barriers to education for people seeking asylum

2. Higher education refers to post-compulsory education at the tertiary level, including university and vocational education.

3. In May 2017, the government announced that all people in the legacy caseload must submit an application for protection by October 1, 2017 or be deported from Australia.

4. A small number of people seeking asylum in Australia are released from immigration detention into "community detention" without a bridging visa. This allows them to live in the community without the right to work. They are effectively barred from higher education, because they are not issued any form of visa while they wait for their refugee claim to be finalized.

5. See https://www.refugeecouncil.org.au/educationsig/ 
in Australia, many prospective students still cannot access scholarships and/or meet university entry requirements (Hartley et al., 2018). Further, our research finds that the challenges of undertaking higher education while seeking asylum can affect the efficacy of scholarships and other institutional supports, significantly affecting educational participation, retention, and success. These findings suggest the critical need for institutional policy-makers to engage with the lived experiences of people seeking asylum and tertiary/community advocates working in this space. Failure to emphasize students' lived experiences can result in well-intentioned yet short-sighted approaches to supporting educational access, which often fail to account for the unique circumstances and material conditions of learners with bridging or temporary visas.

\section{The Invisibility of People Seeking Asylum}

Despite growing awareness of the extreme precarity of people seeking asylum in Australia, their limited access to government services and support, and the psychological impact of trauma and separation from family and community, there is a dearth of research that examines educational access and retention for this population. A significantly larger body of work focuses on the educational experiences of people with refugee status, with research in the tertiary sector exploring student participation, retention, and navigation of institutional, linguistic, and sociocultural practices. This research provides insights into the hardships faced by people with refugee backgrounds, including the educational impact of trauma that results from human rights violations and forced migration, loss of family and community, and disrupted schooling (Naidoo et al., 2014; Naidoo et al., 2018; Sidhu \& Taylor, 2007; Ben Moshe, Bertone, \& Grossman, 2008; Eades, 2013; Earnest et al., 2010; Harris \& Marlowe, 2011; Lenette, 2016; Sladek \& King, 2016).

While research into the engagement of refugee learners in higher education also provides insights into the experiences of other students who have been displaced, the precarity of their presence in Australia means that people seeking asylum encounter additional hardships. Not only are people seeking asylum faced with forced migration and separation from family and community, they are also excluded from the support available to those who have been granted permanent visas, including government assistance with financing tertiary studies. Further, people seeking asylum in Australia remain largely invisible in institutional policies, research, and media coverage (White, 2017). This group experiences unique and significant hardships, but they are frequently subsumed into the broader categories of "refugee," "nonEnglish-speaking background," or "international student" (Terry et al., 2016; White, 2017).
Aside from White's (2017) discussion of the systematic exclusion of people seeking asylum in higher education, the study of Webb et al. (2019) of the admissions practices of an Australian university is a notable exception to the dearth of educational research focusing specifically on this population. Webb et al. (2019) identify how the repurposing of admissions procedures used for other student groups-such as those with international student visas-marginalize and exclude students seeking asylum. Notably, the study also provides insights into strategic employment of "workarounds" by university staff members to overcome barriers in ill-suited admissions practices.

The invisibility of people seeking asylum in Australian popular discourse means that, prior to our study, no national data had been collected on the number of people seeking asylum who were enrolled in higher education, or the numbers of those who would like to pursue tertiary studies. Further, there was no published research on the efficacy of institutional support aimed at the retention, participation, and educational success of this population. Accordingly, there were no clear indicators for how people seeking asylum manage the financial, academic, linguistic, bureaucratic, and sociocultural practices of Australian tertiary institutions, or the impact of being without the support and government services available to other groups in the community.

\section{The Study}

Our research, funded by the National Centre for Student Equity in Higher Education is the first nation-wide review of university and community organization support for people seeking asylum in Australia. We sought to foreground the voices of students, potential students, and staff employed in universities and community organizations, drawing on three main data sources: (1) a national public symposium on access to higher education for people seeking asylum, which was organized by the research team in collaboration with Australian community sector organizations including the Refugee Council of Australia; (2) an online survey of Australian universities and community organizations; and (3) interviews with students seeking asylum, university representatives, and community practitioners.

The national symposium, held in November 2017, brought together 25 people seeking asylum who were currently enrolled in higher education programs, as well as prospective students, and 40 representatives from Australian universities and community organizations. The national online survey drew responses from 67 representatives from 25 Australian universities and 21 community organizations. The survey gathered information on whether universities offered scholarships to people seeking asylum, the numbers of current and graduated students seeking asylum, and institutional 
supports. At the same time, an online survey for community organizations provided insight into the numbers of people seeking asylum who had expressed interest in pursuing higher education, and the community supports in place and those still required.

The data gathered for the quantitative questions in the survey (e.g., whether the university offered full fee-paying/ fee-waiver scholarships; a checklist of the types of support offered to people seeking asylum) was analyzed through descriptive statistics. Responses to questions that allowed for a qualitative answer (e.g., details about the scholarships and the type of support offered, the source and process of funding the scholarship, and the types of community and university partnerships) were initially collated, coded into themes, and quantified where possible.

Semi-structured interviews were also conducted with 11 students who were seeking asylum and either studying or wanting to study at university, 11 representatives from nine universities in five Australian states, and six representatives from community organizations in New South Wales and Victoria. Participants were recruited through their engagement in the symposium, willingness to be interviewed at the end of the survey, or contacts known to the researchers. The interviews were conducted face-to-face or over the phone, and the majority were recorded and transcribed by a professional transcription company. For reasons of sensitivity or perceived risk, some participants requested that notes rather than audio recording - be used during the interview. All the transcriptions or notes of the interviews were sent to participants for member checking, with the invitation to edit or remove text if desired.

We used thematic analysis, as described by Braun and Clarke (2006), adopting a mostly deductive approach to the data, as it allowed for a detailed analysis of the research aims. An inductive element was evident in that some themes that did not fit into a coding frame emerged as the analysis progressed. The initial codes were then reviewed, and themes that overlapped or were insufficiently supported with data were reconsidered. In the final stage, we reviewed the definition and naming of key themes, and then crosschecked and reassessed any themes that were unclear or appeared counterintuitive.

We sought to create a safe space for the research participants to share their perspectives, contending that exploring the experiences of people seeking asylum in institutions like universities can help to "challenge the competing voices that come from [those] more socially powerful" and allow for people's experiences to be elevated (BenEzer \& Zetter, 2014, p. 303). The precarious position of people seeking asylum means that telling their stories can be felt as a risk. Accordingly, we sought to bring participants (students, universities, community organizations) along throughout the study and beyond, through advocacy and practice. However, even with the best of intentions, participatory research can objectify and reduce people from refugee/asylum-seeker backgrounds (Doná, 2007). We have sought to avoid this as much as possible by attempting to maintain reflexivity, and seeking to learn from and with participants throughout each stage of the research (Guillemin \& Gillam, 2004).

\section{Responding to the Complex Financial Situation of People Seeking Asylum}

The financially prohibitive nature of tertiary studies is among the chief barriers identified in our research regarding access to higher education for people seeking asylum in Australia. Accordingly, the most commonly offered form of institutional support is provision of scholarships that cover the full or partial cost of full fee-paying places. At the time of writing, 23 universities across Australia provide scholarships to people seeking asylum, many of which cover the entire cost of tuition for a full fee-paying degree. This response is significant in providing people seeking asylum with opportunities to participate in higher education, despite restrictive government policies, and the competitive tertiary landscape in which reduced funding for undergraduate places has increased a metrics-driven approach to allocation of scholarships. One university staff member described how institutions are keen to respond to the needs of people seeking asylum in their communities, but in doing so, incur significant institutional risk:

The problem is this university is a bit obsessed with retention ... and so they make this really close connection between retention and scholarships being only useful for people who are really high achievers. And so ... they sort of take a risk-management strategy.... [T] hey don't want to be giving money away for somebody who's not going to stick around. (University staff participant, individual interview)

In the current political climate, scholarships for students seeking asylum provide an essential means of access to tertiary studies. University and community organizations who have worked hard to implement these initiatives are to be commended. However, the number of available scholarships does not allow access to higher education for all people seeking asylum who wish to study. Further, our research has shown the importance of considering the unique circumstances of people seeking asylum when determining the nature of such support schemes. Just as the issues that confront people seeking asylum tend to be obscured in the literature and media by greater focus on people with refugee status, appropriating scholarships for students with 
permanent visas can be damaging for those with temporary visa status and fewer government entitlements.

Not only are people who are seeking asylum treated as full-fee paying international students, they also risk losing their government special benefit income support if they engage in tertiary study for longer than 12 months and enrol in a degree program rather than a vocational course that is considered likely to enhance their employment prospects. This financial barrier to education is compounded by the recent removal of Status Resolution Support Services income and casework assistance for people with bridging visas who are deemed to be "job ready" and expected to support themselves if they wish to continue their studies (ACOss, 2018). These policies place people seeking asylum at even greater risk of financial destitution should they pursue university enrolment, eroding the hopeful possibilities that engaging in education should offer.

Even with a full scholarship, students are required to work long hours, often in exploitative jobs, to afford basic living expenses, computers, and other study equipment. The difficulty of balancing education with employment is exacerbated by the requirement for some scholarship recipients to maintain a full-time study load. With limited hours available for employment, some students face homelessness and lack of food, further detracting from their ability to study, and leaving them dependent on charitable organizations such as the Red Cross. As one student participant outlined, "[S]ometimes the money even that Centrelink [the government] were giving, it was just 'cause I was living alone and that was money was exactly for food and just the rent" (student participant, individual interview).

Offering partial or full tuition waivers/scholarships without considering living expenses can therefore have the unintended consequence of financial destitution. While the majority of universities offering full fee-paying/fee-waiving scholarships also provide some form of living allowance, the amount of assistance varies significantly. For example, one university offers a discretionary amount allocated case-bycase, while another offers AUD 7,500 per annum for eligible scholarship holders. Accordingly, scholarship schemes that are successful for students with permanent visas who can access greater financial support from the government may be inappropriate for people seeking asylum.

Some students participating in our study discussed the benefits of part-time degrees that incorporate part-time employment opportunities and subsidized accommodation. Part-time employment can facilitate professional networking and workplace experience while enabling students to meet their living expenses. Other students preferred loans rather than university scholarships, motivated by a desire to reimburse institutions for their education. Such scholarship models may offer useful and sustainable funding alternatives. However, careful consultation of students and staff familiar with the challenges of studying while living on a temporary visa must be central to any scholarship initiatives.

\section{Implementing Appropriate Application Processes}

Financial constraints are not the only barrier to higher education for people seeking asylum. While less visible, accessrelated issues also stem from bureaucratic and administrative processes that are often repurposed from other application types, such as international student entry, or fail to take into account the circumstances of people seeking asylum. Consistent with the findings of Webb et al. (2019), participants in our research identified application procedures as a major institutional barrier, with students describing confusion resulting from inconsistent requirements across institutions, lack of knowledge about processes for enrolment, and difficulties in completing online applications without computer and/or internet access.

According to staff and students, confusion with applications is exacerbated by lack of communication between equity/student welfare services, admissions, and/or international student departments in Australian universities. Students recount the frustration of being turned away by frontline university staff unaware of scholarships for people seeking asylum, or indeed, the differences between visa types. One student commented, "There are different kinds of visas with different conditions, and not many people have the knowledge of the legal differences and what the requirements are" (student participant, individual interview).

Entry to higher education for people seeking asylum is also complicated by some tertiary institutions retaining elements of scholarship application processes used for holders of international student visas, such as imposing an application fee, or requiring evidence of English-language proficiency or right to remain in Australia for the duration of the degree. People seeking asylum are enrolled as international students as a result of their visa status, so the appropriation of existing administrative processes is understandable. However, application processes that are suitable for other groups are often inappropriate for people seeking asylum, who live with visa uncertainty and severe financial constraints, and seldom have documentation. As one student participant advised,

I started looking for scholarships in Australia, but there was confusion whether to apply for international student scholarship or humanitarian scholarship. I am here for humanitarian reasons, but the humanitarian scholarships have some rules that do not apply on me. For example, they require that the applicant hasen't had any degree from Australia, and I do have. For this reason I didn't 
apply for humanitarian scholarships. My only other option is to apply as an international student. (Student participant, individual interview)

When describing their experiences with admissions processes, students identified the importance of receiving one-to-one assistance and encouragement from community organizations and academic staff. One student spoke about the crucial support of an independent counsellor during the application, and a professor who encouraged her to apply for entry to higher education after looking at her transcript. She described this assistance as "the first time someone was treating me like a human being."

Likewise, through casework, community organizations act as trusted brokers, providing one-to-one support for prospective students making application, which often requires students to apply for entry to a degree program and for a scholarship, and to be accepted into the program before being considered for a scholarship. This can be a stressful experience for students who are unable to pay for the degree without financial assistance, and are hesitant to accept a place unless assured of a scholarship. As one community organization staff member advised,

A portfolio within my role was to look at scholarship opportunities, full fee-waivers.... [I]t was only meant to be like 2 hours of my week, but it became a lot, probably took up $80 \%$ of my hours, of my workload, just because of the demand. (Community organization participant, individual interview)

Staff and students also identified the need for more accessible, centralized information on scholarship opportunities. ${ }^{6}$ Students described the difficulty of locating information about higher education in Australia, explaining that many people seeking asylum were unaware of opportunities for participating in further studies:

I asked them [other people seeking asylum] about education, and they said they couldn't [afford to enrol in higher education]. And I said, "Look, there are scholarships." And they were surprised to learn that, because they hadn't been in touch with the Refugee Council; they didn't even know that Refugee Council existed. (Student participant, individual interview)

6. The Refugee Education Special Interest Group, affiliated with the Refugee Council of Australia, has since established a website to provide greater access to current information on scholarship opportunities.

7. For example, enabling courses, which provide a free pathway to university studies for those without the formal qualifications required for entry, or sub-bachelor/diploma programs, offer a discipline-specific certified pathway into undergraduate study (see Baker \& Irwin, 2016).
Given these barriers to enrolment, collaborations between community organizations and university staff are essential to providing people seeking asylum with timely information about scholarships and supports in higher education. However, establishing such relationships is time-consuming, and recent changes to funding have resulted in less capacity in some community organizations to provide this important casework support.

\section{Alternative Entry Pathways and Preparatory Programs}

For many people seeking asylum, particularly those who have not been educated in the Australian schooling system, meeting entry requirements for higher education can be challenging. University entry usually requires an Australian Tertiary Admission Rank or a qualification that demonstrates English-language proficiency. These requirements can be unassailable for many people seeking asylum, who may have experienced interruptions in their education, and for whom financial constraints prevent their enrolment in private language tuition to help them to meet tertiary admission requirements.

Many universities in Australia offer alternative entrance pathways, ${ }^{7}$ including enabling programs, for people who do not meet the traditional admission requirements of a degree program. These alternative entry programs are free for domestic students and help learners become familiar with the academic environment and discipline content of higher education. Importantly, these pathways also involve supports for learners to transition into tertiary studies (Baker \& Irwin, 2016).

However, the temporary visa status of people seeking asylum renders them ineligible for a range of alternative pathways to higher education, some government-funded English language courses, and other programs intended to prepare students for academic studies (Hartley \& Fleay, 2014). Accordingly, community organizations are essential role in helping people seeking asylum to meet university entry requirements, offering preparation for English-language proficiency tests and other forms of tutoring, frequently without government-funded support.

In recognition of the importance of alternative entrance pathways, some universities embed enabling programs into scholarship opportunities for people seeking asylum. Staff and students report that these programs provide valuable 
support for adapting to university systems, navigating online and physical learning spaces, and understanding course expectations, assessment practices, and academic literacy requirements. Navigating these aspects of higher education, which can be overwhelming for all students as they transition into university life, may be particularly challenging for people seeking asylum, who already live in precarious circumstances.

When recounting their first experiences with university life in Australia, many students described feeling overwhelmed and unfamiliar with institutional systems and expectations, having come from a different academic culture and/or having experienced interrupted or minimal prior education. Despite strong motivation to succeed in their studies, unfamiliarity with academic expectations can hinder student outcomes and prevent them from engaging in key learning and assessment. Further, some scholarships require recipients to maintain a minimum grade point average throughout their studies, exacerbating pressure to achieve, despite the unfamiliar academic environment:

I was so agitated at the start.... I missed like online quizzes and all of that because I didn't understand what was expected. And then in second year I started understanding the system more ... mostly through other refugees that were studying there but who were in the second year or third year. (Student participant, individual interview)

University staff and students also emphasize the value of language-transition programs, stressing the need for greater and more specialized English support for people seeking asylum. These supports are particularly important for students who have limited print literacy in their first language(s) (Cranitch, 2010; Hirano, 2014; Windle \& Miller, 2012; Woods, 2009). Embedding alternative pathways and language assistance into scholarship opportunities allows people seeking asylum to access the supports essential to educational retention and success, despite their temporary visa status, which makes them otherwise ineligible for alternative entry options and other preparatory programs. Facilitating such support from peer mentors may also ensure that assistance is relevant and effective. As one student suggested,

The unit which we are doing now, maybe someone from the second year did that unit already, so they can give their tips ... they can share ideas.... I know many students in [name of institution], they are on their own, like the same with my situation.... [W] e are very active studying and we are very, studying very hard but ... at the end they get very, like less marks. So if the universities organized these kind of sessions it will be much easier for students. (Student participant, individual interview)

\section{Facilitating Access to Targeted Mental Health Support}

Students also emphasize the importance of access to counselling services and targeted mental health support throughout their studies. For many people seeking asylum, the mental health impacts of detention, the long-term uncertainty about their future in Australia, and a lack of access to permanent protection and right to family reunion amplify the trauma they experienced in their country of origin and while fleeing. The stresses of adjusting to new academic life, with little time for self-care as a result of the pressures of study and employment, can exacerbate these traumas, frequently resulting in anxiety and depression. As one student described, "You're in a country with no contact, with no community, no family support."

Accordingly, students emphasize the importance of having access to targeted mental health support at university, and the need for counsellors and other staff to become trained in working with people seeking asylum. Such professional expertise requires an understanding of the unique circumstances of living on a temporary visa, which can involve stresses that are different from those confronting people with permanent protection status.

In addition to ensuring that mental health support is relevant to the circumstances and pressures experienced by people seeking asylum, assistance must be highly visible to learners. Some students have described their difficulties accessing mental health support at university: "They do have counselling services-like if someone was facing hardship and things like that. But I only knew about them like second or third year, and by this time it's often too late" (student participant: individual interview). Other students described instances in which people seeking asylum abandoned their studies for lack of academic support and a sense of isolation: "When you're going to uni, it's your first year, you don't know the system. You don't know, like, how it works, and you don't know from where you get the help" (student participant, individual interview).

Yet to access institutional support, often students must disclose their situation, and people seeking asylum may avoid doing so, for fear of being stigmatized.

It was difficult for me to get, to ask for help from non-refugee or people who were, I mean at the very least ... weren't migrants... I was fearful of opening up and telling them I'm a refugee and ... I come to Australia on a boat and spent time in detention because I thought that that would kind of frighten them.... But I mean to get support, it's important that we know each other first. (Student participant, individual interview) 
Some university staff in our study suggested that knowing which students were from asylum seeker backgrounds could allow them to better support learners as they transition into tertiary studies.

I would definitely find it useful if we were to be informed of, you know, the cohort that start here from that background, only because I think it's important that we are proactive, and even if they don't need support at the very early stages but just, you know, making sure that they're aware that support is available. And then they know exactly where to go if they do encounter any challenges. (University staff participant, individual interview)

Yet participants recognized that while staff knowledge of student background may help with timely and effective assistance, such disclosures can be problematic. From a student's perspective, there is a need to avoid public identification of a student's background or inference that such students are "different." Any mechanism to identify students in order to offer support tailored to their unique circumstances needs to be balanced with respect for privacy.

As well as ensuring that universities have online resources and webpages that support people seeking asylum and those with refugee backgrounds, having a dedicated, experienced university staff member who acts as a central contact for people seeking asylum is an important part of continuing support. Such a staff member can also advise students on accessing targeted assistance. As one student expressed it,

[The refugee support person's] job is like to build with refugee students or asylum seekers to help them, you kvnow, where she can. Whenever we have a problem or something, we can discuss with her, and then she organizes an appointment, and then she figures out how she can help, in which way. (Student participant: individual interview)

Although only a few universities that participated in this research provide such support, students and staff reported that such a contact can make substantial difference to the successful transitioning into and through higher education for people seeking asylum. Providing a specialized support person as a central point of contact is therefore a key recommendation for universities to assist students who are often uncomfortable engaging with bureaucracy and encounter challenges "navigating through the university system and the complicated channel [of] ... scholarship provision" (community organization participant, individual interview). Ideally, support staff will include individuals with lived experience seeking asylum. As one community participant advised, "You can't know what it is to be going through this process without having experienced it yourself... When you've had so many knockbacks ... sometimes it seems overwhelming and quite like you've been completely excluded the whole way through" (community organization participant, individual Interview).

\section{Supporting Pathways to Employment}

A major theme to emerge from our work is the need to view participation in higher education in the context of resettlement. Many people seeking asylum see the opportunity to study as important for developing capacities and knowledge to sustain their livelihoods and to contribute to their communities and society. This makes career guidance from pre-entry to post-graduation necessary, ensuring that the choice of degree not only satisfies student interests, but also provides them with a realistic pathway to ongoing employment (Hebbani \& Khawaja, 2018; Hirsch, 2015; Hugo, 2011). Students must have access to targeted career advice and knowledge of the Australian job market to make informed decisions about their professional trajectory, rather than undertaking a course of study because it is dictated by the terms of their scholarship or because it was a strategic option in their country of origin.

Providing targeted career guidance for people seeking asylum necessitates an understanding of the educational needs and professional experiences of students in this group. Staff in community organizations differentiate between students who had established careers and qualifications in their country of origin, and those who completed schooling after arriving in Australia. Individuals in these two groups undertake higher education with distinct background experiences, goals, and learning needs. Those in the former group bring a wealth of professional experience and knowledge but require an Australian qualification to continue working in their chosen profession, while those in the latter group are seeking tertiary education to build a future career. Assistance with career guidance and support for people seeking asylum must therefore take into account the needs and goals of students according to their prior educational experiences, social situation, and professional ambitions.

Accordingly, staff and students emphasize the importance of scholarship programs and targeted entry schemes that provide people seeking asylum with opportunities for workplace experience. University degrees that incorporate a workplace component allow students to establish professional networks and gain industry experience. However, because their visa is temporary, people seeking asylum are frequently ineligible for such opportunities, which are usually reserved for students who have permission to remain in the country. One student described the frustration of being ineligible for a university degree that incorporates a year of 
industry placement - a valuable opportunity to gain paid employment, practical experience, and professional contacts:

When I finished my diploma I applied for the special [degree] of probation accountancy, which is for 4 years.... [T] hey refused my application and then they replied, "You are currently an international student, so you can't do that degree. You have to do like whether bachelor of business majoring in something, or bachelor of accounting." (Student participant, individual interview)

Access to higher education for people seeking asylum should incorporate the same opportunities for industry experience and professional networking that are afforded other students in Australia. Aside from the professional benefits, workplace-integrated degrees can help students make transitions out of higher education, into their professional lives:

Those individuals I've seen really go through setback after setback and apply for every single scholarship opportunity that they can see that is possible. And when they do eventually get in ... it's such a transformative process ... being able to be not just a person seeking asylum and even just to be a student at a university. It reminds the individuals or it affirms them as individuals and as capable, competent, intelligent individuals who have something to contribute and ... that's what's so valuable about this is education really does open doors. (Community organization participant, individual Interview).

\section{Moving Forward with Equitable Access to Higher Education for People Seeking Asylum}

Our study showed that there were 204 people seeking asylum in Australia who were studying at a university on a full feepaying/fee-waiver scholarship as of October 2018 (Hartley et al., 2018). The commitment of these students to education is evident, despite living in uncertain circumstances and being denied access to supports that many others in Australia receive. The universities that offer these scholarships, and the community organizations and individuals that provide advocacy and assistance to enable student access, also need to be commended. Until restrictive government policies are removed, scholarships that cover the full cost of tuition and living expenses are essential for enabling people seeking asylum to access higher education. As identified in this study, their financial situation places people seeking asylum at even greater risk if they attempt to pursue tertiary studies without such supports, eroding the possibilities that engaging in education should offer.

Equitable access to education for people seeking asylum therefore requires urgent changes to federal policies to enable all individuals who have been recognized as refugees to have access to permanent protection visas and the same supports provided to other groups in Australia. Issuing permanent visas to every individual recognized as a refugee would allow people seeking asylum to enter higher education as domestic students, avoiding the need for full-fee/ fee-waiving scholarships and living allowance supports from the university. However, as shown in this study, other institutional assistance is still required to facilitate equitable access to higher education for people seeking asylum.

This research has identified the need for subsidized accommodation and flexible study options incorporating part-time employment and professional experience in the intended workplace. There must also be tailored support for application processes, and an understanding that standard admission processes may be inappropriate for people seeking asylum. Providing a staff member as a central point of reference for students, and professional development for all front-line staff on issues facing people who seek asylum are also essential institutional practices. Alternative entrance pathways, such as enabling programs or diploma pathways, to enable access to undergraduate programs, and ongoing and bespoke language supports and mental health assistance are also needed. Finally, this study has highlighted the importance of providing all students with the information they need to make informed decisions about their academic pathway and professional trajectory.

A major theme emerging from this research is the importance of individual advocates in university and community organizations who help students navigate unfamiliar and complex application procedures. Providing all students with access to one-to-one assistance with support staff who have insights into the unique experiences of people seeking asylum is essential during every stage of engagement in higher education, from admission through to transitioning out of tertiary studies. Student emphasis on the value of such one-to-one assistance for accessing information about educational opportunities and supports also reinforces the importance of collaborations between universities and community organizations. However, forging such relationships in time-poor and underfunded settings can be difficult.

Introducing supports to enable equitable access to higher education for people seeking asylum necessitates first-hand understanding of the challenges confronting this population in Australia. Ensuring those with lived experience of seeking asylum contribute to planning and implementation of inclusion schemes and scholarship opportunities can minimize unintended results of institutional supports that inadvertently compound marginalization, leading to student failure, further distress, and isolation. The experiences and insights of people seeking asylum-including those who have completed tertiary studies, those who withdraw, and those who 
wish to enrol-are therefore essential to informing institutional and community supports for more equitable access to higher education.

\section{References}

Australian Council of Social Service (ACOSs). (2018). Cuts to support system leave people seeking asylum in destitution. https://www.acoss.org.au/media_release/cuts-tosupport-system-leave-people-seeking-asylum-in-destitution/

Baker, S., \& Irwin, E. (2016). Core or periphery? The positioning of language and literacies in enabling programs in Australia. Australian Educational Researcher, 43(4), 487-503. https://doi.org/ 10.1007/s13384-016-0211-x

BenEzer, G., \& Zetter, R. (2014). Searching for directions: Conceptual and methodological challenges in researching refugee journeys. Journal of Refugee Studies, 28(3), 297-318. https://doi.org/10.1093/jrs/feuo22

Ben Moshe, D., Bertone, S., \& Grossman, M. (2008). Refugee access and participation in tertiary education and training. Melbourne: Melbourne Institute for Community, Ethnicity and Policy, Victoria University. https://core. ac.uk/download/pdf/30687021.pdf

Braun, V., \& Clarke, V. (2006). Using thematic analysis in psychology. Qualitative Research in Psychology, 3, 77-101. http://doi.org/10.1191/1478088706qpo630a

Cranitch, M. (2010). Developing language and literacy skills to support refugee students in the transition from primary to secondary school. Australian Journal of Language and Literacy, 33(3), 255-267. https://acuresearchbank.acu.edu.au/item/8593w/developing-language-and-literacy-skills-to-support-refugee-studentsin-the-transition-from-primary-to-secondary-school

Doná, G. (2007). The microphysics of participation in refugee research. Journal of Refugee Studies, 20(2), 210-229. https://doi.org/10.1093/jrs/femo13

Eades, D. (2013). Resilience and refugees: From individual trauma to post-traumatic growth. M/C Journal, 16(5). http://journal.media-culture.org.au/index.php/ mcjournal/article/view/700

Earnest, J., Joyce, A., de Mori, G., \& Silvagni, G. (2010). Are universities responding to the needs of students from refugee backgrounds? Australian Journal of Education, 54(2), 155-174. https://doi.org/10.1177/000494411005400204

Fleay, C., Lumbus, A., \& Hartley, L. (2016). People seeking asylum in Australia and their access to employment: Just what do we know? Cosmopolitan Civil Societies Journal, 8(2), 49-69. http://dx.doi.org/10.5130/ccs.v8i2.4969

Guillemin, M., \& Gillam, L. (2004). Ethics, reflexivity, and "ethically important moments" in research.
Quality Inquiry, 10(2), 261-280. https://doi.org/ 10.1177\%2F1077800403262360

Harris, V., \& Marlowe, J. (2011). Hard yards and high hopes: The educational challenges of African refugee university students in Australia. International Journal of Teaching and Learning in Higher Education, 23(2), 186-196. http:// hdl.handle.net/2292/21747

Hartley, L., \& Fleay, C. (2014). Policy as punishment: Asylum seekers in the community without the right to work. Australia Policy Online. https://apo.org.au/node/38122

Hartley, L., Fleay, C., Baker, S., Burke, R., \& Field, R. (2018). People seeking asylum in Australia: Access and support in higher education. Perth: National Centre for Student Equity in Higher Education, Curtin University, Western Australia. https://www.ncsehe.edu.au/wp-content/ uploads/2018/11/Hartley_PeopleSeekingAsylum.pdf

Hebbani, A., \& Khawaja, N. (2018). Employment aspirations of former refugees settled in Australia: A mixed methods study. Journal of International Migration and Integration, 20(3), 907-924. https://doi.org/10.1007/ s12134-018-0635-4

Hirano, E. (2014). Refugees in first-year college: Academic writing challenges and resources. Journal of Second Language Writing, 23, 37-52. https://doi.org/10.1016/j. jslw.2014.01.001

Hirsch, A. (2015). Barriers to education for people seeking asylum and refugees on temporary visas. Collingwood: Refugee Council of Australia. https://www.refugeecouncil.org.au/barriers-education-seeking-asylum/

Hugo, G. (2011). A significant contribution: The economic, social and civic contributions of first and second generation humanitarian entrants: Summary of findings. Canberra: Department of Immigration and Citizenship. https://www.dca.org.au/sites/default/files/economicsocial-civic-contributions-booklet2011.pdf

Kaldor Centre for International Refugee Law. (2019). Factsheet: The "legacy caseload." https://www.kaldorcentre.unsw.edu.au/sites/default/files/Factsheet_Legacy\%2oCaseload_final.pdf

Lenette, C. (2016). University students from refugee backgrounds: Why should we care? Higher Education Research and Development, 35(6), 1311-1315. ttps://doi.org /10.1080/07294360.2016.1190524

McCarthy, P. K., \& Dauba, I. (2018). How do I pay for my studies in Australia? sBs Punjabi. https://www.sbs. com.au/yourlanguage/punjabi/en/article/2017/11/o1/ how-do-i-pay-my-studies-australia

Naidoo, L., Wilkinson, J., Adoniou, M., \& Langat, K. (2018). Refugee background students transitioning into higher education. Singapore: Springer. https://www.springer. $\mathrm{com} / \mathrm{gp} / \mathrm{book} / 9789811304194$ 
Naidoo, L., Wilkinson, J., Langat, K., Adoniou, M., Cunneen, R., \& D. Bolge. (2014). Supporting school-university pathways for refugee students' access and participation in tertiary education. Kingswood: University of Western Sydney Press. http://www.uws.edu.au/_data/assets/ pdf_file/oo11/830864/Case_Study_Report.pdf

Refugee Council of Australia (RCOA). (2018). With empty hands: How the Australian government is forcing people seeking asylum to destitution. https://www.refugeecouncil.org.au/with-empty-hands-destitution/2/

Sidhu, R., \& Taylor, S. (2007). Educational provision for refugee youth in Australia: Left to chance? Journal of Sociology, 43(3), 283-300. 10.1177/1440783307080107

Sladek, R. M., \& King, S. M. (2016). Hidden from view? Bringing refugees to the forefront of equity targets in Australian higher education. International Studies in Widening Participation, 3(1), 68-77. https://www.linkedin.com/ pulse/bringing-refugees-forefront-australian-highereducation-centre

Terry, L., Naylor, R., Nguyen, N., \& Rizzo, A. (2016). Not there yet: An Investigation into the access and participation of students from humanitarian refugee backgrounds in the Australian higher education system. Report submitted to the National Centre for Student Equity in Higher Education. Perth: Curtin University. https:// www.ncsehe.edu.au/publications/an-investigation-intothe-participation-of-students-of-refugee-backgroundsin-the-australian-higher-education-system/

Webb, S., Dunwoodie, K., \& Wilkinson, J. (2019). Unsettling equity frames in Australian universities to embrace people seeking asylum. International Journal of Lifelong Education, 38(1), 103-120.10.1080/02601370.2018.1559891

White, J. (2017). The banality of exclusion in Australian universities. International Journal of Inclusive Education, 11, 1142-1155. https://doi.org/10.1080/13603116.2017.1350321

Windle, J., \& Miller, J. (2012). Approaches to teaching low literacy refugee-background students. Australian Journal of Language and Literacy, 35(3), 317-333. https://www. researchgate.net/publication/285663356_Approaches_ to_teaching_low_literacy_refugee-background_students

Woods, A. (2009). Learning to be literate: Issues of pedagogy for recently arrived refugee youth in Australia. Critical Inquiry in Language Studies, 6(1/2), 81-101. https://doi. org/10.1080/15427580802679468

Rachel Burke is a senior lecturer at the University of Newcastle. She can be reached at Rachel.Burke@newcastle.edu.au.

Caroline Fleay is associate professor at the Centre for Human Rights Education, Curtin University. She can be reached at c.fleay@curtin.edu.au.

Sally Baker is a senior lecturer in the School of Education at the University of New South Wales. She can be reached at sally .baker@unsw.edu.au.

Lisa Hartley is a senior lecturer at Curtin University. She can be reached at lisa.hartley@curtin.edu.au.

Rebecca Field is a doctoral researcher at Curtin University. She can be reached atbec.field@curtin.edu.au. 